\title{
PLATAFORMAS ONLINE DE MEDIAÇÃO DE CONFLITOS DECORRENTES DE RELAÇÕES DE CONSUMO
}

\author{
ONLINE PLATFORMS FOR THE MEDIATION OF CONFLICTS ARISING \\ FROM CONSUMER RELATIONS
}

\begin{abstract}
João Ricardo Fornazari Bini ${ }^{1}$
Resumo: O presente trabalho objetivou realizar uma breve análise relacionada à mediação online de conflitos decorrentes de relações de consumo no ordenamento jurídico brasileiro, vinculando-se as suas diversas facetas materiais. Além de constar seu aspecto ordinário, mencionou-se o âmbito do Sistema Jurídico Brasileiro através de uma breve abordagem da Lei dos Juizados Especiais e das alterações promovidas no novo Código de Processo Civil, que garantem a presença da mediação logo na gênese processual. Para tanto, foi utilizada a metodologia de revisão bibliográfica, no sentido de conceituar os diferentes institutos presentes nas resoluções alternativas de conflitos e a metodologia explicativa. Constatou-se que, através das novas plataformas de mediação criadas no Brasil, foi reduzida drasticamente a quantidade de processos que seriam distribuídos caso não existissem tais meios. Nesse aspecto, o presente artigo apresenta um breve estudo em relação à grande produtividade na inclusão das plataformas online de mediação para determinados conflitos, em especial nos contratos de relações de consumo, para a busca de implantação de formas alternativas para solucionar questões problemáticas de divergências atuais. Concluiu-se que a mediação online é a melhor forma para solucionar conflitos quando se trata de litígios envolvendo relações de consumo e de vínculos familiares, por permitir a atuação direta das partes em propor uma solução efetiva a casos concretos para evitar demandas judiciais.
\end{abstract}

Palavras-chave: Online; Mediação; Conflitos; Consumo.

Abstract: This work aimed to make a brief analysis related to online mediation of conflicts arising from consumer relations in the Brazilian legal system, linking its various material facets. In addition to its ordinary aspect, the scope of the Brazilian Legal System was mentioned through a brief approach of the Law of Special Courts and the amendments promoted in the new Code of Civil Procedure, which guarantee the presence of mediation in the procedural genesis. For this purpose, the methodology of bibliographic review was used, in order to conceptualize the different institutes, present in alternative conflict resolutions and the explanatory methodology. It was found that, through the new mediation platforms created in Brazil, the number of processes that would be distributed if there were no such means was drastically reduced. In this respect, this article presents a brief study regarding the high productivity in the inclusion of online mediation platforms for certain conflicts, in particular in consumer relations contracts, for the search for alternative ways to solve problematic issues of current divergences. It was concluded that mediation is the best way to resolve conflicts when it comes to disputes involving consumer relations and family ties, by allowing the parties to act directly in proposing an effective solution to concrete cases to avoid lawsuits.

Keywords: Online; Mediation; Conflicts; Consumption.

${ }^{1}$ BINI, João Ricardo Fornazari, Mestrando em Ciências Jurídicas pela Universidade Autónoma de Lisboa, Palácio dos Condes do Redondo, CEP 1169-023, Lisboa, Portugal. E-mail: jr.bini@uol.com.br. ORCID nº. 0000-00022130-1174. 


\section{Introdução}

A sociedade atual é resultante de inúmeros acontecimentos, diretos e indiretos, como a cultura, o hábito, a religião, as normas jurídicas, enfim, o conjunto de determinados tipos de ideologias que, no decorrer dos séculos, arraigaram em nossa perspectiva, tornando como algo usual.

O compartilhamento de ideias consideradas por todos como intrínsecas a uma sociedade permitiu a criação das primeiras civilizações. Assim, a noção de que o conjunto de pessoas é mais produtivo, com maior segurança para o desenvolvimento humano comparado ao setor individual, fez surgir o primeiro formato de contrato social, que, nos ensinamentos de Rosseau (2006), além da segurança social, também nos trouxe alguns problemas.

Nesse sentido, as adversidades da vida em sociedade pressupõem o nascimento de situações conflituosas e conflitantes que geram as pretensões resistidas, conceito clássico de Carnelutti (1999) no que diz respeito à lide.

Com efeito, vivemos atualmente em uma sociedade de massa, caracterizada pelo convívio, pelo vínculo de várias pessoas de diferentes ideologias, inclusive de distintos países, aliados tão somente pela ideia de aldeia global, consumindo, produzindo e distribuindo bens e serviços a nível internacional.

Dentro desse contexto foi desenvolvido o presente trabalho, em especial com relação aos conflitos econômicos advindos das relações de consumo e possíveis meios alternativos de solucioná-los, afastando-se da jurisdição ordinária. Sendo assim, o foco principal foi o estudo do trato dos meios de soluções de conflitos através da mediação exercida mediante as plataformas virtuais (em linha) decorrentes das relações de consumo, pela análise do ordenamento jurídico brasileiro e dos mecanismos atuais criados pelas empresas e governantes para solucionar as controvérsias pela busca em evitar a judicialização dos casos conflitantes no tocante às relações de consumo.

\section{Sociedade de consumo e a problemática da resolução de conflitos}

A sociedade de consumo, conforme aduz Campbell (2001), como se predispõe de sua nomenclatura, é marcada pela comercialização e pelo consumo, especialmente o supérfluo, prevalecendo o ter em detrimento do ser, em razão da valorização extremada a respeito do objeto, se contraposto à pessoa. 
Com efeito, em razão de o mercado de consumo, motriz da economia global, ter por objetivo principal o lucro, há a necessidade do surgimento de proteções legais direcionadas ao polo mais fraco da relação, isto é, o consumidor.

Nesse cenário, visando diminuir a incidência de desigualdades, notadamente quanto à parte mais vulnerável da relação consumerista, surgiu no ordenamento jurídico pátrio o Código de Defesa do Consumidor (BRASIL, 1990).

Deste modo, ao citar o referido texto legal, considera-se consumidor, nos ensinamentos de Netto (2021, pg.136), constante no artigo $2^{\circ}$ da Lei 8078/90, “toda pessoa física ou jurídica que adquire ou utiliza produto ou serviço como destinatário final." Assim, a figura do consumidor, no ordenamento jurídico brasileiro, por pura presunção legal, é estabelecida como a parte vulnerável da relação jurídica, o que permite sua proteção nas relações de consumo em face de grandes empreendimentos.

Houve, também, a criação de diplomas processuais cujos princípios da celeridade, informalidade, simplicidade e oralidade se destacaram, buscando não somente agilizar a atuação jurisdicional nos casos de pouca complexidade, como também levar a efeito a segurança jurídica a todos que a procuram, como ocorre, por exemplo, no caso da Lei dos Juizados Especiais (BRASIL, 1995).

Destaca-se, assim, uma busca para melhor salvaguardar os interesses dos mais frágeis, seja através de diplomas materiais, como no Código de Defesa do Consumidor, seja por estatutos processuais, como na Lei 9.099/90 e no novo Código de Processo Civil, que elencou em seus procedimentos a tutela dos interesses transindividuais, difusos e coletivos.

Entretanto, o que dificulta a solução das lides entre os consumidores advêm, ironicamente, do órgão cuja função precípua é solucioná-las, qual seja, o Poder Judiciário. Com efeito, o alto custo da prestação jurisdicional, aliada à morosidade da solução dos problemas tornam inúmeros casos sem solução, isto associado ao fato de que geralmente os valores dos bens são ínfimos ou de fácil substituição, preferindo o consumidor, não raramente, somente comprar outro produto ou adquirir outro serviço.

Watanabe (2005) refere que Grinover há tempos ressaltava o distanciamento do Poder Judiciário da população. Nesse sentido, os autores apontam como problemas o distanciamento da justiça frente à população, o grande número de processos e demora nas tramitações, além das altas custas de processos, excesso de recorribilidade, burocracia, e outros, o que propicia o interesse pelas vias alternativas de resolução de conflitos. 
A realidade é que, não é conveniente acionar o Poder Judiciário, porquanto o ônus será diametralmente oposto ao bônus, diante da atual sobrecarga laboral que o judiciário brasileiro vem acumulando. Nesse aspecto, a título exemplificativo, observa-se que no ano de 2018 “foram distribuídos 18.747.754 processos, e 19.751.1862 tiveram primeira decisão tendente a pôr fim" (CNJ, 2010, pg.8).

Tais dados, se comparados ao cenário Europeu, deixa claro a razão da morosidade da solução dos processos no Brasil, aliado a cultura do judiciário, que conservam as críticas de grande parte dos brasileiros.

Com relação aos aspectos anuais de distribuições processuais, tomando por base os anos de 2010 a 2018, segundo informações do Conselho Nacional de Justiça:

[...] foram distribuídos mais de 173 milhões de processos e julgados mais de 166 milhões, sendo 153 milhões de competência não criminal e 20 milhões criminais, aproximadamente. Nota-se, nesse período, a melhora na capacidade de julgamento em que o aumento do número de processos julgados $(22,25 \%)$ superou o aumento dos processos distribuídos (9,39\%). Assim, o acervo de processos não julgados no período de 2010 a 2018 foi de aproximadamente 6,9 milhões, dos quais 5 milhões são de competência não criminal (CNJ, 2010, pg.8).

Porém, o Brasil, um dos países que mais possui produtividade para julgamento no mundo, é considerado um dos que mais possui acervo e processos sem solução.

Desse modo, uma simples análise de tais números demonstra que há de se buscar meios viáveis para solução do conflito, com métodos alternativos como a mediação, a arbitragem e a conciliação extrajudicial, com o objetivo de desjudicializar ao máximo quanto possível o poder judiciário.

\section{A mediação como método mais adequado de solução de conflitos de consumo}

A mediação, assim como a arbitragem e a conciliação, é uma alternativa extrajudicial para solução de conflitos. Nos ensinamentos do Professor Bahamonde (2018, pg. 6-7), a mediação é um processo de "autotutela que conta com a presença de um terceiro imparcial e independente, o mediador, que os auxilia na tentativa de um acordo final sobre o objeto em litígio".

Para a professora Cruz (2018, pg. 24), a mediação é exercida através de "um terceiro independente, neutro e imparcial (o mediador), que auxilia as partes na busca de um consenso, tentando restaurar a comunicação e o diálogo." 
Na legislação positivada brasileira, nos termos do parágrafo único do artigo $1^{\circ}$ da Lei 13.140/15, a mediação é, sem prejuízo das noções doutrinárias anteriormente descritas, em linhas literais, a atividade técnica exercida por terceiro imparcial sem poder decisório, que, escolhido ou aceito pelas partes, as auxilia e estimula a identificar ou desenvolver soluções consensuais para a controvérsia (BRASIL, 2015).

Insta salientar que muito embora a Lei 13.140/15 trate da mediação, ela não foi a primeira legislação relacionada ao tema que existiu no Brasil. No sistema judicial brasileiro, a mediação teve abordagem inicial legislativa através do Projeto de Lei $n^{\circ} .4 .827 / 98$, cuja proposta trazia os pilares da mediação no Brasil. A exemplo de outros semelhantes, tal projeto, no entanto, não prosseguiu. Assim, somente com a positivação da Lei $\mathrm{n}^{\circ}$. 13.140/15 é que a mediação foi efetivamente criada no ordenamento jurídico brasileiro, havendo discussões de sua aplicação desde o ano de 1998 (PINHO, 2008).

Em que pese existir similaridades entre os elementos caracterizadores da mediação com o instituto da arbitragem, verifica-se que aquela ainda é o método mais adequado para solução dos conflitos originários de relações de consumo.

Nas palavras de Almeida (2018, pg. 36), a arbitragem é: “[...] um meio de resolução alternativa de litígios, à semelhança da mediação, da negociação e, na perspectiva de alguns autores, da conciliação judicial."

$\mathrm{Na}$ arbitragem, no entanto, há a atuação de um terceiro, intitulado como árbitro, caso tenham as partes, no negócio jurídico, ou em apartado, estipulado uma cláusula de reserva da arbitragem (convenção de arbitragem), legitimando a atuação do árbitro para solução do conflito.

Nesse contexto, a convenção de Arbitragem, nos ensinamentos de Almeida, pode ser considerada um reflexo da autonomia de vontade das partes. Ou seja:

A convenção de arbitragem é o reflexo da autonomia das partes e o fundamento da arbitragem voluntária, encontrando-se prevista nos artigos $1^{\circ}$ da LAV e $7^{\circ}, n^{\circ} 1$ da UNCITRAL. No fundo, podemos defini-la como a expressão da vontade das partes no recurso à arbitragem para solução de seus litígios. Trata-se, por isso, de condição - sine qua non - da arbitragem voluntária [...] (ALMEIDA, 2018, pg. 46).

Conforme aduz Ventura (1986, pg. 301): “Com a convenção a celebração da convenção de arbitragem nasce um direito potestativo [...] cujo conteúdo consiste na faculdade de fazer constituir um tribunal arbitral." 
A solução do conflito por meio da arbitragem se convalida através de uma sentença arbitral, sem prejuízo dos despachos e das decisões interlocutórias, conforme aduz Faria (2014), discorrendo acerca dos pronunciamentos do árbitro.

A sentença arbitral, no Brasil, com fundamentos nos artigos 32 e 33 da Lei 9.307/1996, possui natureza de título executivo, com prerrogativa de imutabilidade da decisão arbitral, ressalvadas as hipóteses de nulidade formal do título ou subjetiva do árbitro, de modo que rege a condição de imutabilidade da decisão arbitral.

Neves (2020, pg.78), sobre a executividade do título, expõe que: “[...] a decisão que resolve a arbitragem é atualmente uma sentença arbitral, não mais necessitando de homologação pelo juiz para ser título executivo judicial, o que significa a sua equiparação com a sentença judicial”. Nota-se, portanto, através da figura do árbitro, demasiada burocracia, o que acaba por fazer as partes menos interessadas em um litígio desistir da busca de seu direito. No entanto, contrariamente à arbitragem, na mediação isso não ocorre, o que permite uma solução célere, sem demasiada oficialidade, o que tem gerado consequências positivas tanto para as partes, quanto para o Poder Judiciário.

No que se relacionam as pessoas, estas, normalmente desinteressadas em ajuizar um processo judicial, através da mediação conseguem a solução de seu problema, não poucas vezes sem pretensão resistida.

Em suma, no que diz respeito à arbitragem, conquanto configure um meio que visa desjudicializar as lides, desafogar o judiciário e permitir a tutela ampla e efetiva da função judicante, não é a melhor escolha para promover soluções para as relações de consumo, se comparada à mediação.

Isso se dá possivelmente por influência do método de solução dado pela mediação. Cruz (2018) aduz que se trata de opção das partes, onde estas, conjuntamente, buscam a melhor solução do conflito, auxiliadas pelo terceiro mediador. Nesse contexto:

A lei define mediação como a forma de resolução alternativa de litígios, realizada por entidades públicas ou privadas, através do qual duas ou mais partes em litígio procuram voluntariamente alcançar um acordo com assistência de um mediador de conflitos. O mediador coloca as partes no centro da solução do conflito que as opõe (através da técnica do empowerment) e dota-as das ferramentas necessárias para que possam resolver seu dissídio através de um acordo que verdadeiramente as satisfaz (CRUZ, 2018, pg. 24).

Em síntese, a mediação possibilita aos litigantes solucionarem a causa litigiosa sozinhos, sem auxílio de um terceiro, diferenciando-se claramente da arbitragem, uma vez que esta exige 
que o terceiro, o árbitro, decida a causa. No primeiro caso há aconselhamento e, no segundo, decisões.

Existem, também, razões de cunho contratual aplicadas nas relações entre particulares, subsistidas da autonomia privada, que encontram limites nas relações de consumo no âmbito judicial. No entanto, a mediação permite o livre exercício da autonomia privada, o que vai ao encontro das mais atuais técnicas de solução de conflito.

Com efeito, o conceito de autonomia privada há muito é discutido na doutrina, cujo significado não é unívoco. Carvalho (2017, pg. 13), acerca de tal concepção, aduz: "Pode, portanto, dizer-se que a autonomia privada corresponde a uma área de licitude - ou a um espaço de liberdade -, dentro da qual as pessoas ou certas categorias de pessoas dispõem da possibilidade de praticar os atos que entenderem."

Neste aspecto, a mediação, por permitir a resolução do litígio através de condição não judicial, oferece às partes a oportunidade de pactuarem entre si pela melhor solução, exaltando a autonomia privada, apoiada nos pareceres do mediador.

Ademais, se analisados os elementos da arbitragem, verifica-se a motivação especial sobre o porquê de uma mediação ser mais benéfica para solução dos conflitos do que a arbitragem: a substitutividade da vontade das partes pela decisão do árbitro pode vir a causar uma judicialização, mesmo que mais célere, porquanto existente título judicial. Vale lembrar que os próprios princípios basilares da arbitragem traduzem determinada continuidade de burocracia, que poderia vir a desgastar ainda mais a relação entre as partes, o que não chega a ocorrer diante da mediação.

Por outro lado, a mediação permite que as partes cheguem a um consenso sem necessitar acionar o poder judiciário, ou demasiada burocracia, seja na forma executiva, seja na forma de conhecimento, além de valorizar a vontade decisória das partes, sem ocorrer a substitutividade, ocasionando, via de consequência, maiores chances de evitar futuros conflitos.

Nesse mesmo sentido, entende Cruz (2018), senão vejamos:

A melhor forma de resolver conflitos é aquela em que as partes se sentem parte da solução ao invés de parte do problema. A mediação presume que os intervenientes serão as pessoas mais competentes para tomar as decisões determinantes de sua vida. $O$ fato de a mediação restaurar o diálogo, não impondo uma solução, faz com que se torne numa forma mais apelativa de justiça (CRUZ, 2018, pg. 26).

Frise-se, ainda, o fato de que a mediação pode ser criada pelo governo, pelo setor acadêmico, pelas faculdades, assim como pelos próprios empreendedores, visando salvaguardar os interesses de seus clientes, o que faz aumentar a recepção de seus produtos. 
Destarte, a mediação, atualmente, é o meio de solução de conflito mais eficaz para solucionar litígios advindos das relações de consumo.

\section{Plataformas virtuais (em linha) de mediação no Brasil: considerações sobre a legalidade e efetividade}

A mediação, conforme mencionado, está condicionada à presença de um terceiro independente e imparcial, que age em auxílio às partes para que estas ponham fim a um conflito entre elas existente. Contudo, este terceiro não age em substitutividade à vontade das partes, mas tão somente as condiciona, de forma indireta, que a conciliação é ou será o melhor meio de solução da questão intrincada.

A Lei 13.140/2015, especificamente no artigo $9^{\circ}$, exige da pessoa interessada em exercer a mediação somente sua capacidade civil, a confiança das partes e a capacitação para exercer o encargo, independentemente de ser membro de qualquer classe, entidade ou associação ou de se inscrever em uma das citadas entidades (BRASIL, 2015).

Portanto, diante do fato de inexistir exigências além das já expostas, a amplitude dos legitimados para exercer a mediação é patente, de modo a possibilitar que ela seja feita por uma autoridade pública ou servidor público, a serviço do governo, ou particular, por pessoas capacitadas, no âmbito empresarial, acadêmico ou social. Não há exigências superiores para que o interessado no exercício da mediação atue, exceto a licenciatura adequada para o ato, em entidade reconhecida pelo Ministério da Justiça, para que sua mediação tenha força executiva. Mediadores não necessitam estar vinculados a qualquer entidade, associação ou classe para que exerçam o encargo. Diante disso, não há óbice para criação de localidades próprias para exercerem mediação, desde que os mediadores sejam devidamente capacitados para o ato.

A par disso, inúmeros sistemas de resolução de conflitos surgidos de relação de consumo despontaram ao decorrer dos anos, ainda mais com a enorme expansão tecnológica deste território, seja em âmbito nacional, elencando nesta concepção o Brasil, seja internacionalmente, nas demais pessoas jurídicas de direito público externo, em seu sentido lato.

Com efeito, há a necessidade da análise de alguns destes programas, apontando os seus respectivos dados, para o fim de verificar, empiricamente, a qualidade, eficácia e produtividade de resolução das demandas postas à sua análise, nos setores públicos e particulares. 
No âmbito da legislação brasileira, o Conselho Nacional de Justiça determinou, através da Resolução $\mathrm{n}^{\circ}$ 125, de 29 de novembro de 2010, a instauração de políticas públicas voltadas para resolução alternativa de conflitos, baseado no artigo $5^{\circ}$, inciso XXXV, da Constituição de 1988, que estabelece ser direito fundamental a razoável duração do processo (CNJ, 2010). Considera a referida Resolução que, por ser função precípua do judiciário a pacificação social através da aplicação da lei nos casos concretos fomentar práticas alternativas de solução de problemas, a fim de não só concretizar o princípio citado, como também efetivar a tutela jurisdicional.

Nos termos do artigo $1^{\circ}$, parágrafo único da referida Resolução, verifica-se que cabe aos órgãos judiciários, além da solução adjudicada, oferecer outros mecanismos de solução de controvérsia. Neste mesmo parágrafo a Resolução elenca como meios alternativos a conciliação, a mediação e a arbitragem.

No entanto, a mera exposição abstrata não soluciona as lides, devendo ser também delineados critérios práticos para instrumentalizar o fim que se almeja. Assim, os artigos $3^{\circ}$ a $5^{\circ}$ da mesma Resolução indicam a necessidade de firmar parcerias com entidades públicas e privadas para fornecer à população métodos alternativos à solução dos conflitos, afirmando como principal foco das parcerias "a formação de nova mentalidade voltada aos métodos de pacificação; o incentivo à autocomposição, baseado na Resolução $n^{\circ}$ 125/10 do Conselho Nacional de Justiça e na Lei 13.140/15; a aproximação dos planos pilotos das atividades judiciais, nos moldes do artigo 334 do Código de Processo Civil”.

Para obtenção dos objetivos perseguidos pela Resolução n $125 / 10$ do Conselho Nacional de Justiça, estabeleceu-se exemplos de entidades que poderiam vir a ser utilizadas, através da formação de parceria, para aplicação dos objetivos e medidas para soluções alternativas de conflito, sendo elas: universidades; grandes litigantes; câmaras privadas e órgãos representantes e sindicatos, federações e confederações.

Através da abordagem geral iniciada pela Resolução nº 125/10 do Conselho Nacional de Justiça, inúmeras iniciativas começaram a ser criadas no Brasil.

Tais casos ressaltam as parcerias formadas entre órgãos governamentais e entidades de apoio, sem deixar de lado as iniciativas das empresas privadas em aderir a métodos alternativos para solução de conflitos.

Referida Resolução, ainda, abriu a possibilidade para as empresas se reestruturarem, no sentido de adicionar em seus serviços locais próprios para solução de problemas através da mediação. Nesse sentido, o artigo $8^{\circ}, \S^{\circ}$ estabelece a possibilidade dos Tribunais criar e 
promover a justiça itinerante, enquanto não devidamente instalados os serviços de mediação e arbitragem, seja no contexto do judiciário, seja através de parcerias.

Essa modalidade, como se pressupõe a nomenclatura, é aquela que não se encontra fixa em determinado local. Portanto, pode ser exercida através de automóveis, barcos, enfim, qualquer meio que leve à população a possibilidade de solução da lide que não a judicialização.

Demonstrou-se, até o momento, as medidas criadas pelo poder público, com apoio de entidades privadas e públicas, em fomentar as práticas alternativas de resolução de conflitos utilizando-se de meios físicos para tanto. No entanto, o meio físico, em nossa atualidade, se fosse privativa sua utilização, não conseguiria abranger a todos, notadamente pela extensão territorial do Brasil e pela quantidade de questões problemáticas existentes na sociedade de massa e de consumo, devendo não somente ressaltar a utilização da tecnologia, como a implementar.

Neste ínterim, vejamos os sistemas criados para apreciação dos conflitos, levando-os a conciliação ou a mediação.

Em 20/05/2019, em parceria do Conselho Nacional de Justiça e da Secretaria Nacional de Proteção ao Consumidor, o órgão do Ministério da justiça assinou um acordo de cooperação para solução de causas que envolvam controvérsias consumeristas. Com esse acordo, criou-se a plataforma consumidor.gov.br, vinculada ao Processo Judicial Eletrônico. À época da assinatura, ressaltou-se que as relações de consumo são as causas que mais criam acervo processual no Brasil, sendo, em média, $10 \%$ do total.

O sistema criado, neste breve hiato temporal, não demorou a demonstrar resultados. Somente no ano de 2019, 565 empresas e 1.510.276 de usuários se cadastraram no sistema, bem como foram resolvidas 2.090.249 reclamações recebidas.

Ainda nessa seara, o Conselho Nacional de Justiça entabulou um acordo com o Banco Central e a Federação Brasileira de Bancos, para resolução dos conflitos de consumo surgidos.

Com base nesse sistema de proliferação da conciliação e da mediação utilizado nas relações de consumo, outros setores do direito buscaram o mesmo trajeto. Destarte, instauraram-se os sistemas de Mediação Comunitária, visando fortalecer os laços sociais, convertendo os conflitos em oportunidade capacitativa para os atores locais.

E ainda, surgiu o sistema de Mediação e Direito Urbanístico, com fundamento na Resolução 87 do Conselho Nacional das Cidades, recomendando ao Ministério das Cidades a aprovação e a aplicação de diretrizes públicas visando à prevenção e solução de conflitos fundiários mediante a mediação. Ainda nesse contexto, nasceu o programa Mediação nas Escolas, promovendo a defesa e a luta contra o bullying e o programa Mediação no Trânsito, 
com apoio da Polícia Militar, de modo itinerante, procurando solucionar discussões no cenário do tráfego. Enfim, são inúmeros os programas criados para levar à população outra forma de resolução de conflito, ressaltando, por fim, a Mediação Familiar, a Mediação Empresarial, Mediação e Direito Notarial, etc.

Como se nota, é possível verificar a tentativa de promover modificações no pensamento da população brasileira, a fim de conter a busca, quase sempre primária, ao Poder Judiciário. Ademais, é cediço que o problema de acúmulo de processos, escassa mão de obra por questões orçamentárias, aliada ao fato da enorme centralização de lides no Judiciário não é problema exclusivo do Brasil. Outros países também sofrem com os mesmos problemas, eis que a política pública para gerar a diminuição da judicialização é questão intrincada global.

Cruz (2018) refere ser a mediação familiar a medida mais expressiva utilizada pelo poder público, ou por particulares em exercício dessa ilustre função, a maneira mais eficaz de solução dos conflitos, pois como anteriormente exposto, permite-se às partes não somente a possibilidade de participar do conflito, mas sim de ativamente influir na decisão, uma vez que o mediador, terceiro imparcial, somente as auxiliará para busca da melhor solução no dissídio.

Vejamos, portanto, seu posicionamento:

A melhor forma de resolver conflitos é aquela em que as partes se sentem parte da solução, ao invés de parte do problema. [...] O problema da mediação familiar é o de superar o dissídio, permitindo que as partes (com auxílio do mediador) tentem lograr um acordo, ao invés de viverem resignadas e frustradas com um desfecho heterocompositivo. Para tanto, é necessário focar nos interesses e não nas posições (CRUZ, 2018, pg.26).

E arremata:

A mediação familiar é o meio de resolução alternativa de lítigios de âmbito privilegiado na esfera dos conflitos familiares, uma vez que estes são dotados de características emocionais próprias que os tornam mais adequados a outra sede que não a judicial (CRUZ, 2018, pg.26).

Com efeito, verifica-se que no Brasil tem cada vez mais se tornado comum a utilização da mediação no âmbito familiar, tendo em vista a alteração procedimental do Código de Processo Civil no que se relaciona ao Procedimento Comum. Por ser este o mais amplo e complexo procedimento processual existente, visou-se, desde sua gênese, estabelecer a conciliação e a mediação. Assim, nos termos do artigo 334 do Código de Processo Civil Brasileiro, recebida a inicial, o juiz determinará à citação da parte adversa para comparecer à audiência de conciliação e mediação.

Acredita-se que através dessa mudança legislativa tenha possibilitado uma diminuição do acervo processual no Brasil, que já se encontra extremamente abarrotado. Entretanto, ainda não 
é permitida a mediação nos processos criminais. Consigne-se que essa restrição diz respeito ao instituto da mediação, porquanto há possibilidade da composição civil entre o autor do fato e a vítima, notadamente no âmbito da Lei 9.099/95.

O Código de Processo Civil estabelece a Conciliação e a Mediação desde o início da ação, como também pelo rito do Juizado Especial Cível, da Lei no 9.099/95 (BRASIL, 1995), que além de primar pelos princípios da oralidade, celeridade, economia processual, informalidade e simplicidade, impulsiona a conciliação e a mediação quase que em integralidade (BRASIL, 2015).

Destarte, resta claro que a mediação, devidamente instrumentalizada e posta à disposição da sociedade, possibilita a diminuição dos casos judicializados, mesmo se, a priori, seja realizada por quem seja parte do órgão, ou entidade vinculada a ele, sendo irremediavelmente correto expor sua utilidade para solução de litígios, seja na forma preventiva ou na forma conciliatória.

O que se busca, portanto, é diminuir drasticamente o número de processos em trâmite e, consequentemente, o acervo, permitindo aos juízes tempo para julgar casos complexos que dependam, intrinsecamente, da prestação da tutela jurisdicional.

Aliado a utilidade da mediação, urge ressaltar sua legalidade. Como já demonstrado, essa modalidade alternativa de resolução de conflitos encontra respaldo em vários diplomas legais, como o Código Civil, o Código de Processo Civil, e a Lei ${ }^{\circ}$ 13140/15, que conferem força normativa de sentença aos acordos intermediados pelo mediador, de modo a salvaguardar a executividade do título em caso de descumprimento. Destarte, alia-se em uma só modalidade a utilidade, legalidade e efetividade, promovendo as garantias constitucionalmente previstas às partes e permitindo, por via oblíqua, o desafogo do judiciário.

\section{Conclusão}

No presente trabalho, buscou-se estudar as formas alternativas de resolução de conflito, especificamente a respeito da mediação.

Conforme demonstrado, esta é uma modalidade da referida forma alternativa, consistindo na atuação de um terceiro, licenciado através de uma entidade pública ou privada autorizada no ensino, devidamente reconhecido pelo órgão governamental responsável, que auxilia as partes a chegarem a realizar a autocomposição, emitindo apontamentos voltados a especificar os malefícios da judicialização da lide e dos benefícios que a solução consensual trará para pacificação social e conclusão da controvérsia. 
Com efeito, observa-se que a mediação é o método alternativo de solução de conflito mais eficaz para as questões relacionadas ao consumo, porquanto evita a morosidade da prestação jurisdicional e o alto custo para movimentação da máquina estatal, com a possibilidade da realização da autocomposição não apenas por órgãos públicos, mas também por entidades privadas, até mesmo pelas próprias empresas, que objetivam melhor atender seus clientes.

Nesse cenário, verifica-se que as partes, auxiliadas pelo mediador, fazem suas próprias escolhas, incutindo a ideia de maior efetividade, porquanto não será um terceiro que decidirá a circunstância, mas sim elas próprias. Essa ideia de solução própria aduz maior segurança no cumprimento do que se conciliou, porque revestida da participação consensual das partes. Ademais, soma-se a esses argumentos a possibilidade de uma resolução do conflito ocorrer dentro da própria empresa, exaltando a praticidade.

Além disso, fundado nos argumentos que a mediação é o melhor método para solução do litígio envolvendo relações de consumo, visualiza-se a aplicação das plataformas virtuais e físicas criadas no Brasil.

Ressaltou-se, ainda, a figura dos sistemas de Mediação Itinerante, Mediação Comunitária, Mediação Privada no âmbito das relações de consumo, bem como a figura do site especializado em mediação criado através da parceria do Conselho Nacional de Justiça e da Secretaria Nacional de Proteção ao Consumidor, ligada ao Ministério da Justiça.

Por meio da análise dos referidos programas, em especial de forma online, vinculado também à utilização da mediação de forma endo e exo processual, chegou-se a conclusão de que a referida modalidade tem servido para diminuir a quantidade de processos existentes.

Conforme explanado, no Brasil, mais de dois milhões de casos envolvendo questões de consumo foram solucionados apenas em 2019 com a plataforma virtual do Conselho Nacional de Justiça e do Governo Federal.

Diante de todo exposto, conclui-se que a mediação, se devidamente instrumentalizada e colocada à disposição da sociedade de modo acessível e efetivo, especialmente de forma virtual, poderá ser um sistema para amparar o Poder Judiciário em seu maior problema, o acúmulo de lides para julgamento.

Assim, com a criação das plataformas virtuais eficazes e disponibilização de profissionais qualificados, a maioria dos conflitos das relações de consumo, sem olvidar de sua aplicação para outros setores, poderiam ser solucionados antes da judicialização, o que melhoraria cabalmente a prestação jurisdicional e, por conseguinte, a celeridade e efetividade dos processos. 


\section{Referências}

ALMEIDA, Daniela Vicente de. O dever de revelação como problema de independência e imparcialidade dos árbitros. Coimbra: Almedida, 2018.

BRASIL. Constituição (1988). Constituição da República Federativa do Brasil:

promulgada em 5 de outubro de 1988. Disponível em: <

http://www.planalto.gov.br/ccivil_03/constituicao/constituicao.htm>. Acesso em: 10/11/2020.

CAMPBELL, Colin. A ética romântica e o espirito do consumismo moderno. Rio de Janeiro: Rocco, 2001.

CARNELUTTI, Francesco. Teoria geral do direito. São Paulo: Ed. Lejus, 1999.

CARVALHO, Jorge Morais - Os limites à liberdade contratual. Coimbra: Almedina, 2017.

CONSELHO NACIONAL DE JUSTIÇA. Resolução nº 125/10. Dispõe sobre a Política

Judiciária Nacional de tratamento adequado dos conflitos de interesses no âmbito do Poder

Judiciário e dá outras providências. Disponível em: < https://www.cnj.jus.br/wp-

content/uploads/2014/04/resolucao_125_29112010_23042014190818.pdf>. Acesso em:

10/11/2020.

CRUZ, Rossana Martingo. A mediação familiar como meio complementar de justiça. Coimbra: Almedina, 2018.

FARIA, Marcela Kohlbach de. Ação anulatória da sentença arbitral: aspectos e limites. Brasília, DF: Gazeta Jurídica, 2014.

BRASIL. Lei $n^{\circ}$ 8.078/90. Dispõe sobre a proteção do consumidor e dá outras providências. Disponível em: < http://www.planalto.gov.br/ccivil_03/leis/18078compilado.htm>. Acesso em: $10 / 11 / 2020$.

Lei no 9.099/95. Dispõe sobre os Juizados Especiais Cíveis e Criminais e dá outras providências. Disponível em: <http://www.planalto.gov.br/ccivil_03/_ato20152018/2015/lei/113105.htm>. Acesso em: 10/11/2020.

. Lei ${ }^{\circ} 13.140 / 15$. Dispõe sobre a mediação entre particulares como meio de solução de controvérsias e sobre a autocomposição de conflitos no âmbito da administração pública; altera a Lei $\mathrm{n}^{\circ}$ 9.469, de 10 de julho de 1997, e o Decreto $\mathrm{n}^{\circ} 70.235$, de 6 de março de 1972; e revoga o $\S 2^{\circ}$ do art. $6^{\circ}$ da Lei $n^{\circ} 9.469$, de 10 de julho de 1997. Disponível em:

<http://www.planalto.gov.br/ccivil_03/_ato2015-2018/2015/lei/113105.htm>. Acesso em: $10 / 11 / 2020$.

. Lei no 13.105/15. Código de Processo Civil. Disponível em:

<http://www.planalto.gov.br/ccivil_03/_ato2015-2018/2015/lei/113105.htm>. Acesso em: $10 / 11 / 2020$.

NEVES, Daniel Amorim Assumpção. Manual de direito processual civil. 12a ed. Salvador: Jurpodvm, 2020.

NETTO, Felipe Braga. Manual de Direitos do Consumidor: à luz da jurisprudência do STJ. $16^{\mathrm{a}}$ ed. Salvador: Juspodvm, 2021.

NOTÍCIAS DO PORTAL. Integração do Consumidor.gov.br ao PJ e irá diminuir judicialização entre empresas e consumidores. Disponível em:

https://www.defesadoconsumidor.gov.br/escolanacional/cursos/84-noticias-do-portal/1127integracao-do-consumidor-gov-br-ao-pje-ira-diminuir-judicializacao-entre-empresas-e- 
consumidores > . Acesso em: 10/11/2020.

PINHO, Humberto Dalla Bernardina; et al. Teoria geral da mediação: à luz do projeto de lei e do direito comparado. Rio de Janeiro: Lumen Juris, 2008.

ROUSSEAU, Jean-Jacques. O contrato social. Tradução de Tiago Rodrigues da Gama. São Paulo: Russel, 2006.

VENTURA, Raúl. Convenção de Arbitragem. Rev. Ordem dos Advogados. Lisboa: Ordem dos Advogados. 2:46(1986) 289-350. Disponível em: https://portal.oa.pt/upl/\%7B1fb76b36575c-4576-8102-6b41e874c208\%7D.pdf. [Consult. em 10-11-2020].

WATANABE, Kazuo. Acesso à justiça e sociedade moderna. In: GRINOVER, Ada Pellegrini; DINAMARCO, Candido Rangel. Participação e processo. São Paulo: DPJ, 2005. 